\title{
Prevention of Clostridium difficile-induced experimental pseudomembranous colitis by Saccharomyces boulardii : a scanning electron microscopic and microbiological study
}

\author{
Françoise Castex, ${ }^{1 *}$ Gerard Corthier,${ }^{2}$ Sylvie Jouvert,${ }^{1}$ Gary W. Elmer,${ }^{2} \dagger$ \\ FrançoIS LUCAS $^{2}$ and MADEleine Bastide ${ }^{1}$ \\ ${ }^{1}$ Unité de Recherche en Immunologie, Faculté de Pharmacie, Université de Montpellier I, \\ 34060 Montpellier Cedex 1, France \\ ${ }^{2}$ Laboratoire d'Ecologie Microbienne INRA, CRJ, 78350 Jouy-en-Josas, France
}

(Received 23 November 1989; revised 3 February 1990; accepted 8 February 1990)

\begin{abstract}
The ability of Saccharomyces boulardii to protect mice against intestinal pathology caused by toxinogenic Clostridium difficile was studied. Different regions of the intestine of experimental mice were prepared for observation by scanning electron microscopy or homogenized for $\boldsymbol{C}$. difficile enumeration and quantification of toxin A by enzyme immunoassay and toxin B by cytotoxicity. The test group was treated for $6 \mathrm{~d}$ with an $S$. boulardii suspension in drinking water and challenged with $C$. difficile on day 4 . The three control groups were: axenic mice, mice treated with only $S$. boulardii and mice only challenged with $C$. difficile. The results showed that: (i) $70 \%$ of the mice infected by $C$. difficile survived when treated with $S$. boulardii; (ii) the $C$. difficile-induced lesions on the small and large intestinal mucosa were absent or markedly less severe in $S$. boulardii-treated mice; and (iii) there was no decrease in the number of $C$. difficile but rather a reduction in the amount of toxins $A$ and $B$ in $S$. boulardii-treated mice.
\end{abstract}

\section{Introduction}

Clostridium difficile is the causative agent of antibioticassociated diarrhoea and pseudomembranous colitis in human and animals (Bartlett, 1986). This bacterial species produces two antigenically and biologically distinct toxins implicated in the pathogenesis of these diseases (Banno et al., 1984; Bartlett et al., 1978; Lyerly et al., 1986). Toxin A has enterotoxic and weakly cytotoxic activities and causes fluid accumulation and mucosal damage in several animal models (Banno et al., 1984; Mitchell et al., 1986). Toxin B has potent cytotoxic activity and alters the morphology of a variety of cultured cells (Banno et al., 1984; Meador \& Tweten, 1988; Sullivan et al., 1982). Toxins A and B act synergistically when injected into the intestine (Lima et al., 1988; Lyerly \& Wilkins, 1984). These toxins are lethal for rabbits, mice, hamsters and monkeys (Arnon et al., 1984; Libby

$\dagger$ Present address: Department of Medical Chemistry BG20, University of Washington, Seattle, WA 98195, USA.

Abbreriation: SEM, scanning electron microscopy. et al., 1982; Lonnroth \& Lange, 1983; Lyerly et al., 1985). The pathological effects and death are only observed when both toxins are present (Czuprynski et al., 1983; Lyerly et al., 1985; Wilson et al., 1986).

The lesions produced by these bacteria in man can be reproduced in the well-defined gnotobiotic rodent model. Pseudomembranes have been described in such a model (Czuprynski et al., 1983; Wilson et al., 1986). It has been shown that Saccharomyces boulardii has a protective effect against $C$. difficile infections (Corthier et al., 1986; Elmer \& McFarland, 1987; Massot et al., 1984; Toothaker \& Elmer, 1984), but the direct effect of the yeast on the mucosal surface has never been studied. We have described, however, the kinetics of $S$. boulardii transit in the mouse intestine by scanning electron microscopy (Castex et al., 1987, 1988).

The aim of the work reported here was to study the mucosal lesions produced after inoculation of $C$. difficile into the intestine of gnotobiotic mice and the effect of preventive treatment by $S$. boulardii. The relationship between topographical histology of the mucosa, multiplication of $C$. difficile and the amounts of toxins A and B was investigated. 


\section{Methods}

Clostridium difficile. Strain VPI 10463 (VPI) originally isolated from an abscess, was provided by N. M. Sullivan, Virginia Polytechnic Institute and State University, Blacksburg, Virginia, USA (Czuprynski et al., 1983).

Experimental schedule and animals. $\mathrm{C} 3 \mathrm{H} / \mathrm{He}$ axenic mice were reared in Trexler-type isolators fitted with a rapid transfer system (La Calhène, France). They were fed ad libitum a commercial diet (RO3-40, UAR, Villemoisson, France) sterilized by gamma irradiation. The experiments were performed over a $6 \mathrm{~d}$ period using four groups of 10 mice each; three groups served as controls and one group for the assay. The axenic control mice did not receive any treatment. The $C$. difficile control mice were challenged by the orogastric route on day 4 with $0.5 \mathrm{ml}$ of a fresh culture (approximately $10^{8}$ viable bacteria), and the $S$. boulardii control mice received the yeast in drinking water during the experimental period (Corthier et al., 1986). For the assay group, mice were treated for $6 \mathrm{~d}$ with $S$. boulardii and challenged with $C$. difficile on day 4. At the end of the treatment, the intestinal tract was removed. For scanning electron microscopy, the following samples $(0.5 \mathrm{~cm})$ were taken: duodenum $(0.5 \mathrm{~cm}$ after the pylorus), jejunum $(11 \mathrm{~cm}$ after the pylorus), ileum ( $1 \mathrm{~cm}$ before the caecum), caecum (in the middle) and colon $(1 \mathrm{~cm}$ after the caecum). The remaining parts were used for bacterial counts and toxin assays. To avoid nonspecific modification of the gut mucosa, intestinal samples were never removed from dead mice but only from healthy or dying mice.

Scanning electron microscopic (SEM) examinations. The specimens were fixed in $1 \%(\mathrm{v} / \mathrm{v})$ glutaraldehyde for $1 \mathrm{~h}$ and washed in $0.2 \mathrm{M}-$ sodium cacodylate buffer, $\mathrm{pH} 7 \cdot 2$. After stepwise dehydration through a series of graded ethanol solutions, the specimens were coated with gold to a thickness of about $30 \mathrm{~nm}$ using a Balzers SCD 020 ion sputter and then examined with a Cambridge Stereoscan model 100 scanning electron microscope (Castex et al., 1987, 1988).

C. difficile counts and toxin assays. The samples were weighed and homogenized. Bacterial counts were performed under anaerobic conditions as described previously (Corthier et al., 1985). Toxin A was measured by an immunoenzymic assay (Mahé et al., 1987). Samples were treated with a trypsin inhibitor (soybean type I-S; Sigma) at a final concentration of $1 \mathrm{mg} \mathrm{ml}^{-1}$. Results were expressed in terms of $\left.\log _{10}[\mathrm{ng} \text { (g of gut sample) })^{-1}\right]$. The cytotoxic effect of toxin $\mathrm{B}$ was assayed in tissue culture (Corthier et al., 1985). The cytotoxic titres were transformed into amounts of toxin B expressed in terms of $\log _{10}[\mathrm{ng}$ ( $\mathrm{g}$ of gut sample) $)^{-1}$ (Corthier et al., 1989).

\section{Results}

\section{Survival}

All the axenic mice and $S$. boulardii control mice survived. All the $C$. difficile control mice were moribund and would have died from the infection (Corthier et al., 1985) had they not been killed for the SEM and biological examinations of their gut. In the assay group, protected by treatment with $S$. boulardii and challenged with $C$. difficile, seven of the ten mice survived.

\section{SEM examinations}

The caecum of the axenic mice showed regular and voluminous folds on a continuous cellular surface (Fig.
$1 a)$; in the $S$. boulardii control mice, the caecum had the same appearance but it was covered with yeasts (Fig. $1 b$ ). The caecum taken from dying $C$. difficile control mice was completely destroyed and perforated. The cellular surface was disrupted and covered by debris. The bacteria, distributed on the surface singly or in groups, were easily detectable (Fig. $1 c$ ). In the mice protected with $S$. boulardii and challenged with $C$. difficile, the mucosal surface of the caecum was almost normal. The cellular surface was not affected and both bacteria and yeasts were visible (Fig. 1d). In the colon, the same features as in the caecum were observed in each group of mice but to a lesser degree. The mucosa of colons taken from dying $C$. difficile control mice had lesions and the bacteria were easily detectable (Fig. 1e). In $S$. boulardiiprotected mice, the colon was normal and both bacteria and yeasts were visible (Fig. $1 f$ ).

In the small bowel, the same results were obtained with the duodenal, jejunal and ileal mucosal sections; therefore, only the results for the jejunum are discussed. The jejunal mucosa of the axenic mice showed regular tongues and finger-like villi; the villi were covered with yeasts in the $S$. boulardii control mice. In the $C$. difficile control mice, the jejunal mucosa taken from dying mice, even though far from the site of bacterial multiplication, showed lesions, which were mainly localized on the top of the villi (Fig. 1 g). C. difficile could not be detected. In the $S$. boulardii-protected mice, the jejunal mucosa was normal and neither bacteria nor yeasts were found (Fig. $1 h)$.

\section{Bacterial count and toxin amounts}

Numbers of bacteria and amounts of toxins A and B in the digestive tract are presented in Table 1. C. difficile counts in the digestive tract were similar in dying control mice and in the assay group (surviving mice). Multiplication of the bacteria occurred mainly in the caecum and the colon. No toxin could be detected in the jejunum in either group of mice. Large quantities of both toxins were present in the caecum and the colon of dying mice, but no (or very little) toxin could be detected in these regions of the gut in protected mice. The reduction of toxin production due to $S$. boulardii treatment ranged from 100- to 1000 -fold.

\section{Discussion}

The lethal effect of inoculation of gnotobiotic mice with the VPI strain of $C$. difficile has already been reported (Corthier et al., 1985; Czuprynski et al., 1983; Vernet et al., 1989; Wilson et al., 1986); histological staining showed pseudomembranes, extensive inflammation and abrasion of the mucosal surface (Czuprynski et al., 1983; 

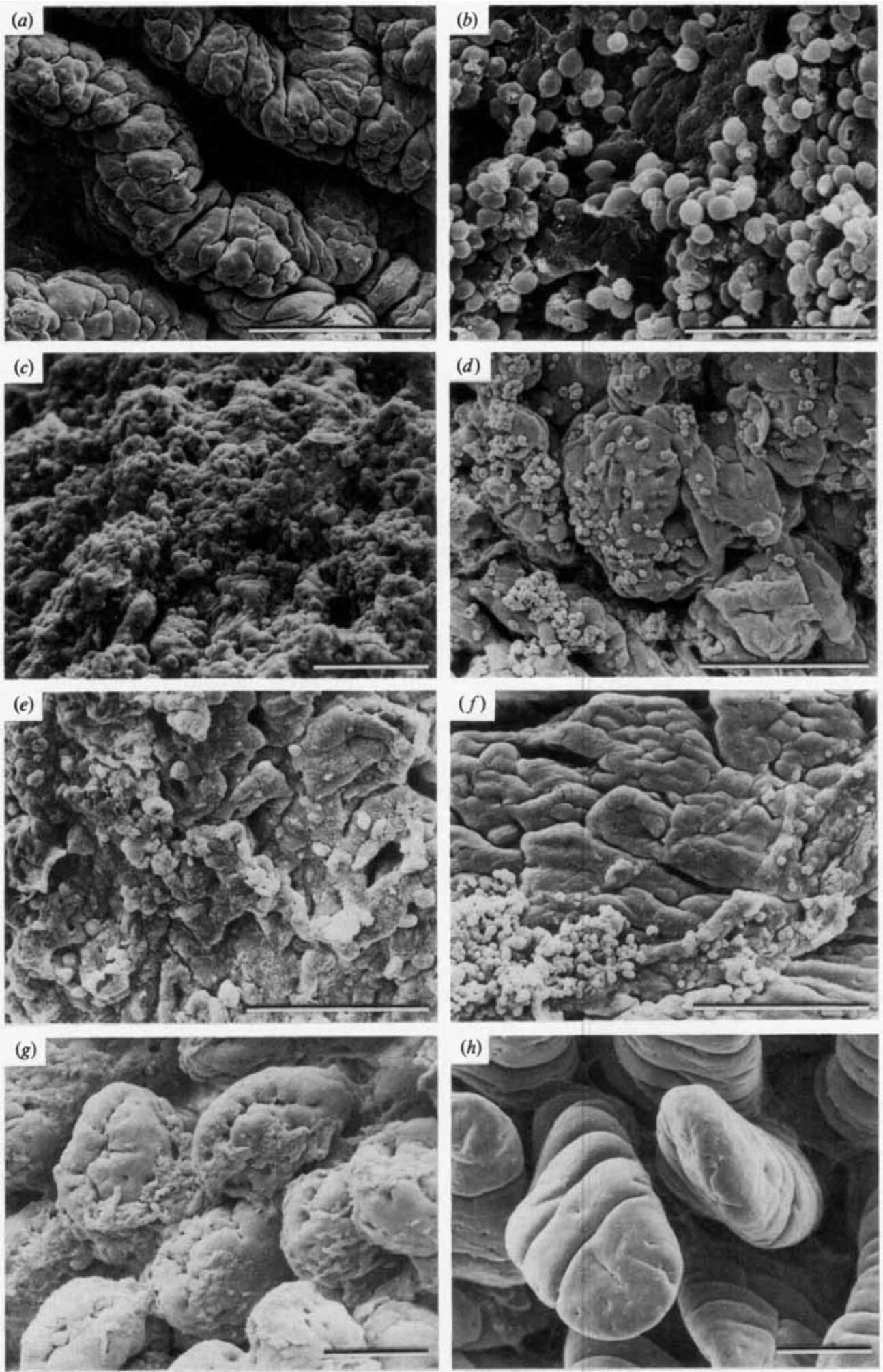

Fig. 1. Scanning electron micrographs of : $(a-d)$ caeca of axenic control mice ( $a ;$ bar, $200 \mu \mathrm{m}), S$. boulardii control mice $(b ;$ bar, $20 \mu \mathrm{m})$, $C$. difficile control mice $(c ;$ bar, $50 \mu \mathrm{m})$ and $S$. boulardii-protected mice $(d ;$ bar, $50 \mu \mathrm{m}) ;(e, f)$ colons of $C$. difficile control mice $(e ;$ bar, $50 \mu \mathrm{m})$ and $S$. boulardii-protected mice $(f ;$ bar, $50 \mu \mathrm{m}) ;(g, h)$ jejuna of $C$. difficile control mice $(g ;$ bar, $50 \mu \mathrm{m})$ and $S$. boulardii-protected mice $(h ; \mathrm{bar}, 50 \mu \mathrm{m})$. 
Table 1. Numbers of bacteria and amounts of toxins $A$ and $B$ in the intestinal mucosa of $S$. boulardii-treated mice challenged with $C$. difficile

\begin{tabular}{lccc}
\hline Sample* & Bacterial count $\dagger$ & Toxin A $\ddagger$ & Toxin B $\ddagger$ \\
\hline Jejunum & & & \\
$\quad$ Control mice & $4.5 \pm 0.2$ & $<1.0$ & ND \\
$\quad$ Treated mice & $4.6 \pm 0.2$ & $<1.0$ & ND \\
Caecum & & & \\
$\quad$ Control mice & $8.4 \pm 0.1$ & $3.0 \pm 0.5$ & $3.3 \pm 0.1$ \\
$\quad$ Treated mice & $8.2 \pm 0.2$ & $<1.0$ & $0.9 \pm 0.3$ \\
Colon & & & \\
$\quad$ Control mice & $8.3 \pm 0.2$ & $2.6 \pm 0.5$ & $2.3 \pm 0.3$ \\
$\quad$ Treated mice & $8.0 \pm 0.2$ & $<1.0$ & ND \\
\hline
\end{tabular}

* The control mice received only $C$. difficile; they were all moribund at the time of sampling. The $S$. boulardii-treated mice for which results are presented all survived the challenge with $C$. difficile.

$\left.\dagger \log _{10}[\text { no. of viable bacteria ( } \mathrm{g} \text { of gut sample) })^{-1}\right]$ (mean \pm standard error).

$\ddagger \log _{10}$ [ng toxin ( $\mathrm{g}$ of gut sample) $\left.)^{-1}\right]$ (mean \pm standard error). ND, Not detected.

Vernet et al., 1989). The present SEM study permitted a detailed visualization of the villus surface, revealing the complete disruption of the villus structure and release of the internal components in the caecum and colon. It also revealed a previously unknown effect, namely that $C$. difficile caused lesions in the small intestine even though bacterial multiplication was four orders of magnitude lower there than in the caecum or the colon. Although this pathology was slight, it was significant.

Our study confirmed the protective effect of $S$. boulardii treatment on mice challenged with toxinogenic C. difficile (Corthier et al., 1986), and showed that this effect was associated with a marked reduction of both toxin A and B production. Similar effects were observed in this animal model using different protective agents such as some bacterial species dominant in the human flora (Corthier et al., 1985) or an adapted diet (Mahé et al., 1987). Until the present study, it was not known whether protected mice develop a transient non-fatal disease. Indeed, one can postulate that, even with protective $S$. boulardii treatment, a slight, undetectable, production of toxins may occur and cause a non-lethal disease. The topographical studies clearly showed the absence of detectable pathological processes in protected mice, suggesting that even if toxin was produced, it remained below the pathological level. The mechanism of $S$. boulardii protection is under investigation.

In conclusion, $S$. boulardii reduced the mortality of mice challenged by toxinogenic $C$. difficile. In protected mice, the intestinal mucosa was practically undamaged and this protection was not due to a decrease in $C$. difficile number but rather to reduced toxinogenesis. It remains to be determined whether $S$. boulardii protection against $C$. difficile in man is associated with a decrease in the amounts of toxin $\mathbf{A}$ and $\mathbf{B}$ and intestinal protection as it is in the animal model.

We thank Dr S. L. Salhi for helpful advice in the preparation of this manuscript and $\mathrm{Mr}$ G. Nabias for highly qualified assistance in performing the scanning electron microscopic examinations.

\section{References}

Arnon, S. S., Mills, D. C., Day, P. A., Henrickson, R. V., Sullivan, N. M. \& WILKINS, T. D. (1984). Rapid death of infant rhesus monkeys injected with Clostridium difficile toxins $\mathrm{A}$ and $\mathrm{B}$ : physiologic and pathologic basis. Journal of Pediatrics 104, 34-40.

Banno, Y., Kobayashi, T., Kono, H., Watanabe, K., Ueno, K. \& Nozawa, T. (1984). Biochemical characterization and biologic actions of two toxins (D-1 and D-2) from Clostridium difficile. Reviews of Infectious Diseases 6, S11-S20.

Bartlett, J. G. (1986). Clostridium difficile: pseudomembranous colitis and antibotic-associated diarrhea. In Infectious Diarrhea, pp. 157-178. Edited by S. L. Gorbach. Boston: Blackwell Scientific Publications.

Bartlett, J. G., Chang, T. W., Gurwith, M., Gorbach, S. L. \& ONDERDONCK, A. B. (1978). Antibiotic-associated pseudomembranous colitis due to toxin-producing clostridia. New England Journal of Medicine 298, 531-536.

Castex, F., Jouvert, S. \& Bastide, M. (1987). Visualization by scanning electron microscopy of the intestinal transit of Saccharomyces boulardii in mice. Bulletin de la Société Française de Mycologie Médicale 16, 249-256.

Castex, F., Jouvert, S. \& Bastide, M. (1988). Kinetics of elimination of Saccharomyces boulardii in the mouse ileum: visualization by scanning electron microscopy. Revista Iberica de Micologia 5, (suppl.), 28 (Abstract).

Corthier, G., Dubos, F. \& Raibaud, P. (1985). Modulation of cytotoxin production by Clostridium difficile in the intestinal tracts of gnotobiotic mice inoculated with various human intestinal bacteria. Applied and Environmental Microbiology 49, 250-252.

Corthier, G., Dubos, F. \& Ducluzeau, R. (1986). Prevention of Clostridium difficile-induced mortality in gnotobiotic mice by Saccharomyces boulardii. Canadian Journal of Microbiology 32, 894-896.

Corthier, G., Muller, M. C., Elmer, G. W., Lucas, F. \& DubosRAMARÉ, F. (1989). Interrelationships between digestive proteolytic activities and production and quantitation of toxins in pseudomembranous colitis induced by Clostridium difficile in gnotobiotic mice. Infection and Immunity 57, 3922-3927.

Czuprynski, C. J., Johnson, W. J. \& Balish, E. (1983). Pseudomembranous colitis in Clostridium difficile monoassociated rats. Infection and Immunity 39, 1368-1376.

Elmer, G. W. \& MCFarland, L. V. (1987). Saccharomyces boulardi suppression of overgrowth of toxigenic Clostridium difficile following vancomycin treatment in the hamster. Antimicrobial Agents and Chemotherapy 31, 129-131.

Libby, J. M., JoRTNeR, B. S. \& Wilkins, T. D. (1982). Effect of two toxins of Clostridium difficile in antibotic-associated cecitis in hamsters. Infection and Immunity 36, 822-829.

Lima, A. A. M., Lyerly, D. M., Wilkins, T. D., InNes, D. J. \& GUERRANT, R. L. (1988). Effects of Clostridium difficile toxins A and $B$ in rabbit small and large intestine in vivo and on cultured cells in vitro. Infection and Immunity 56, 582-588.

LonnRoth, I. \& Lange, S. (1983). Toxin A of Clostridium difficile: production, purification and effect in mouse intestine. Acto Pathologica et Microbiologica Scandinavica 91, 395-400.

LYERLY, D. M. \& WiLKINS, T. D. (1984). Characteristics of the toxins of Clostridium difficile. In Antibiotic-associated Diarrhea and Colitis, pp 89-102. Edited by S. P. Borriello. Boston: Martinus Nijhoff. 
Lyerly, D. M., Saum, K. E., MacDonald, D. K. \& Wilkins, T. D. (1985). Effects of Clostridium difficile toxins given intragastrically to animals. Infection and Immunity 47, 349-352.

Lyerly, D. M., Phelps, C. J., Toth, J. \& Wilkins, T. D. (1986) Characterization of toxin $\mathrm{A}$ and $\mathrm{B}$ of Clostridium difficile with monoclonal antibodies. Infection and Immunity 54, 70-76.

MAhÉ, S., CoR THIER, G. \& DUBOS, F. (1987). Effect of various diets on toxin production by two strains of Clostridium difficile in gnotobiotic mice. Infection and Immunity 55, 1801-1805.

Massot, J., Sanchez, O., Couchy, R., Astoin, J. \& Parodi, A. L. (1984). Bacterio-pharmacological activity of Saccharomyces boulardii in clindamycin-induced colitis in the hamster. Arzneimittel Forschung 34, 794-797.

MEador, J. \& TWeten, R. K. (1988). Purification and characterization of toxin B from Clostridium difficile. Infection and Immunity 56 $1708-1714$.

Mitchell, T. J., Ketley, J. M., Haslam, S. C., Stephen, J., Burdon, D. W., Candy, D. C. A. \& Daniel, R. (1986). Effect of toxins A and B of Clostridium difficile on rabbit ileum and colon. Gut 27, 78-85.
Sullivan, N. M., Pellett, S. \& Wilkins, T. D. (1982). Purification and characterization of toxins $\mathrm{A}$ and $\mathrm{B}$ of Clostridium difficile. Infection and Immunity 35, 1032-1040.

ToothakeR, R. D. \& Elmer, G. W. (1984). Prevention of Clindamycin-induced mortality in hamster by Saccharomyces boulardii. Antimicrobial Agents and Chemotherapy 26, 552-556.

Vernet, A., Corthier, G., Dubos-Ramare, F. \& Parodi, A. L. (1989). Relationship between levels of Clostridium difficile toxin A and toxith $\mathrm{B}$ and cecal lesions in gnotobiotic mice. Infection and Immunity $\mathbf{5 7}$, $2123-2127$.

Wilson, K. H., Sheagren, J. N., Freter, R., Weatherbee, L. \& LYERLY, D. (1986). Gnotobiotic models for study of the microbial ecology of Clostridium difficile and Escherichia coli. Journal of Infectious Diseases 153, 547-551. 